\title{
Mapeamento do uso de mídias sociais no segmento de vestuário no alto vale do Itajaí
}

Mapping out the use of social media by members of the clothing industry from Alto Vale do Itajaí.

Lisandra de Andrade Dias

Doutorado em Engenharia de Produção - (UFSC) lisandra.andrade@gmail.com

Luan Eder Bonezzi Gomez

pós-graduado em Design Gráfico - Produção Publicitária UNIDAVI luanbgomez@gmail.com 


\section{Mapeamento do uso de mídias sociais no segmento de vestuário no alto vale do Itajaí \\ Mapping out the use of social media by members of the clothing industry from Alto Vale do Itajaí. Innovation}

Lisandra de Andrade Dias e Luan Eder Bonezzi Gomez

\section{Resumo}

Este artigo teve como objetivo o mapeamento do uso de mídias sociais no segmento de vestuário do Alto Vale do Itajaí por meio de uma pesquisa qualiquantitativa. $\mathrm{O}$ universo pesquisado é constituído por 43 empresas associadas ao Sindicato das Indústrias da Fiação, Tecelagem, Confecção e do Vestuários do Alto Vale do Itajaí, e cinco não associadas, mas consideradas expressivas na região. Com os resultados do mapeamento, podese verificar a viabilidade de definições de estratégias de comunicação e a possibilidade de proposição de planejamento estratégico digital de gestão de design para as empresas locais, que pouco vem explorando as mídias sociais. Embora já exista uma conscientização sobre a importância das mídias sociais, é perceptível a falta de profissionalismo na área. Assim, surge um campo fantástico a ser explorado por profissionais capacitados: a possibilidade da definição de estratégias de comunicação e marketing, bem como a realização da gestão de design.

Palavras- chave: Mídias Sociais; Gestão de Design; Planejamento Estratégico Digital.

\begin{abstract}
This article's goal was to map out the use of social media by the clothing industry from Alto Vale do Itajaí by means of a qualitative-quantitative research. The research field consists of 43 enterprises associated to the local trades union (Sindicato das Indústrias da Fiação, Tecelagem, Confecção e Vestuários do Alto Vale do Itajaí) and 5 non-affiliated, but considered regionally significant. By analyzing the mapping's results, the authors were able to verify the viability of communication strategies' definitions and the possibility of proposing a digital strategic plan for design management to the local companies, that have been poorly exploring social media. Although there is already perceived awareness of its importance, there's also a noticeable lack of professionalism in this area. Therefore, this appears to be a fantastic field to be harvested by qualified professionals, who can create and define communication and marketing strategies and, altogether, work with design management.
\end{abstract}

Keywords: Social Media; Design Management; Social Media Strategy Planning Process. 


\section{Introdução}

Em um cenário empresarial competitivo, ter presença online se tornou algo imprescindível para a conexão entre uma empresa, serviço ou produto com o seu público-alvo.

De acordo com Torres (2009), podemos definir mídias sociais como sites na internet que permitem a criação e o compartilhamento de informações e conteúdos nos quais o consumidor é, ao mesmo tempo, produtor e consumidor da informação; são essas: Facebook, Twitter, Instagram e outras, que têm demonstrado um crescimento exponencial em número de usuários e tempo que eles passam usufruindo deste serviço.

Em 2014, por exemplo, um estudo realizado pela agência de marketing We Are Social apontou que o Brasil, com uma população de 204 milhões, tinha 110 milhões de usuários de Internet. Desses usuários, 96 milhões - ou seja, 47\% da população total possuíam perfis em redes sociais. Esse mesmo público respondeu que, em média, ficava $5 \mathrm{~h} 26$ conectado à Internet e gastava $3 \mathrm{~h} 47$ por dia com acesso às redes sociais via mobile ou computador fixo.

Levando em conta dados como esses, pode-se considerar as mídias sociais como ótimas redes para o uso de marketing, comunicação e publicidade, já que boa parte da população brasileira está presente nesse meio e passa um elevado tempo diário conectado.

As mídias sociais podem ser utilizadas por qualquer empresa ou segmento, porém o presente artigo tem como objetivo mapear seu uso pelo segmento de vestuário do Alto Vale do Itajaí.

O segmento de vestuário foi escolhido por sua importância na região, mais precisamente em Rio do Sul, cidade polo do Alto Vale do Itajaí. Conforme França (2014), as atividades de confecção de artigos do vestuário representam importante parcela da economia de Rio do Sul, em termos de postos de trabalho, número de estabelecimentos e arrecadação de tributos.

O mapeamento do uso das mídias sociais pelo segmento de vestuário do Alto Vale do Itajaí permitirá a análise da realidade do segmento nas mídias sociais para que, desta forma, considere-se a possibilidade e a viabilidade de estratégias de comunicação, e juntamente, a realização da gestão de design de marcas e/ou empresas. 


\section{MÍDIAS SOCIAIS}

Telles (2011) explica que várias pessoas confundem os termos redes sociais e mídias sociais, muitas vezes usando-os de forma indistinta, embora não sejam sinônimos. O primeiro é uma categoria do segundo. De acordo com o autor, sites de relacionamento ou redes sociais são ambientes cujo foco é reunir pessoas, os chamados membros, e as mídias sociais são sites na Internet construídos para permitir a criação colaborativa de conteúdo, a interação social e o compartilhamento de informações em diversos formatos, nas quais o usuário é ao mesmo tempo produtor e consumidor da informação.

A agência We Are Social destaca que entre as mídias sociais mais usadas pelos brasileiros estão: o Facebook com 25\% do total; Google +, 13\%; Twitter com 11\%; Instagram, 10\%; LinkedIn com 9\%; Pinterest, 6\%; e Badoo com 6\%, dentre outras.

Segundo Torres (2009), as mídias sociais têm um poder formador de opinião e podem ajudar a construir ou destruir uma marca, portanto ficar de fora das mídias sociais significa abdicar de um espaço importante na mídia e desperdiçar essa comunicação. Os clientes das empresas presente em mídias sociais estão lendo e falando sobre o mercado em que ela atua, seus produtos e também os produtos do concorrente, queira a empresa ou não, ela participando ou não.

Dessa forma, é possível imaginar o "perigo" de um determinado usuário publicar sua opinião negativa sobre uma marca ou empresa nas mídias sociais e a mesma não estar lá para avaliar e atuar sobre o comentário. Talvez uma opinião apenas não faça diferença, mas se compartilhada, curtida e comentada, pode se tornar negativa para uma marca. A presença das empresas e marcas nas mídias sociais é de suma importância para que seja feito um monitoramento da opinião do cliente/consumidor.

Além de monitorar os comentários que surgem sobre ela, uma empresa conectada transmite uma boa imagem para o seu público, pois demonstra preocupação com a opinião dele, consolidando assim seu nome ou marca. De acordo com Gunelius (2012), a conversação com os usuários nas mídias sociais é a maneira perfeita de tornar uma marca conhecida, ampliar o seu reconhecimento já existente e seu recall e oportunizar a fidelidade.

Em um local que existe público engajado e uma boa plataforma de criação e divulgação, as possibilidades de estratégias são grandes. O alcance do marketing 
aumenta; é possível multiplicar o número de visitas em uma loja virtual da marca, encontrar novos clientes, divulgar novidades, produtos, promoções e lançamentos, e manter-se atualizado quanto às ações dos concorrentes, etc.

\section{ESTRATÉGIA DIGITAL NAS MÍDIAS SOCIAIS}

Segundo Palermo, da empresa Talk2, a estratégia digital é a consolidação da estrutura e das políticas de uma empresa para chamar a atenção, criar canais de diálogo e falar com o consumidor por meio da Internet. As estratégias digitais usam os canais digitais para duas funções: disseminar mensagens e estabelecer conversas com pessoas estratégicas para a organização, sejam clientes, parceiros ou apoiadores. Ambos os pontos são interdependentes em um planejamento, já que conteúdo sem interação perde força e não chama a atenção. Interação sem conteúdo é vazia e pouco atrativa.

As etapas essenciais para uma estratégia digital ou de marketing digital nas mídias sociais são: o planejamento, a execução e o monitoramento.

\subsection{PLANEJAMENTO}

Como em qualquer outro plano, deve-se começar entendendo a realidade da empresa em questão. É fundamental conhecer a situação atual da empresa, o que será trabalhado e para quem isso será difundido. Quanto mais aprofundada for essa fase de planejamento, mais fluidos serão os outros passos. A partir daí, são elencados os seguintes pontos: Descobrir quem é o público-alvo, afim de determinar quais os canais a serem utilizados, os conteúdos que serão produzidos e o tom de conversa da empresa na web; Produção de personas, com o intuito de orientar as políticas editoriais e adaptação das estratégias de conteúdo; e Verificação da concorrência, buscando saber como é trabalhada sua comunicação digital e para quem o conteúdo é focado.

Saber e determinar quais os objetivos da empresa ou marca nas mídias sociais é outro fator a ser considerado na parte de planejamento. Conforme Gunelius (2012), determinar seus objetivos pode influir imensamente sobre o tipo de conteúdo a ser publicado e na escolha do tipo das atividades das quais participa nas mídias sociais. 
Ainda, é preciso definir objetivos e metas a serem atingidas em um determinado tempo com essa estratégia, estipulando indicadores mensuráveis, baseados no seu negócio e que possam ser acompanhados. Por fim, pode-se planejar como será o visual das páginas ou perfis nas mídias sociais, afim de que fiquem alinhadas com a comunicação e identidade visual da empresa.

A partir de um planejamento bem construído, levando em conta o perfil da empresa, quais são suas necessidades, objetivos, o público-alvo, as ações nas mídias sociais e de que maneira, entre outros pontos, começa-se a execução deste planejamento.

\subsection{EXECUÇÃO}

O primeiro passo basicamente seria a criação dos perfis e páginas da empresa ou marca nas mídias sociais. Assim que criados as páginas e perfis nas mídias sociais, a empresa deve ter em mente que, desde o começo, estará envolvida em canais nos quais não poderão limitar-se a atualização de conteúdo e publicação. A empresa deve lembrar que, na Web 2.0, não se pode apenas enviar informação - ela recebe e deve lidar com as mensagens e os comentários dos usuários. É preciso destacar alguém da sua equipe para observar as redes e dar atenção aos usuários que enviam mensagens.

Essa constante interação nas mídias sociais garante a boa utilização delas. Segundo Gunelius (2012), o simples fato de ouvir e compreender nas mídias sociais contribui para o crescimento dos negócios - do mesmo modo que oferecer descontos e lançar promoções.

Paralela a essa constante interação com os usuários, existe a criação de conteúdo nas mídias sociais escolhidas para a empresa ou marca em questão. O tipo de conteúdo e o tom de voz de comunicação já devem ter sido escolhidos no planejamento. Em se tratando de conteúdo, é importante produzi-lo pensando no público alvo da marca ou empresa e que ele seja relevante.

Um grande diferencial é a originalidade na criação dos materiais e ações, que estejam focados no público-alvo da empresa ou marca em questão e na mídia social escolhida. Isso demanda tempo e especialização, afinal a empresa deve produzir materiais apropriados e adaptados para seus diferentes canais online. Uma página em uma mídia social mais visual, por exemplo, pode demandar infográficos e/ou 
fotografias. As peças gráficas apresentam diferenças técnicas e comunicacionais de acordo com a características de cada mídia social.

\subsection{MONITORAMENTO}

As mídias sociais escolhidas dentro de um planejamento devem ser monitoradas, afinal se a estratégia não estiver apresentando resultado é preciso repensar uma nova ação. Monitorar, controlar e mensurar deve ser algo repetido constantemente nas mídias sociais.

Segundo Torres (2009), a Internet, por ser baseada em uma rede de computadores e servidores, permite que se implementem diversos tipos de estratégias de monitoramento e medição. Essa habilidade própria da Internet deve ser utilizada em toda sua potencialidade, pois trará mais eficiência.

Sem uma estratégia de monitoramento bem definida, perde-se a oportunidade de criar uma estratégia de aprendizado com seu consumidor, que pode melhorar as ações de marketing, como também de gerar um diferencial competitivo em relação aos concorrentes.

A partir do monitoramento podem surgir novas ideias, que podem mostrar um novo caminho. Dados como: as fontes de tráfego, o tempo de navegação e o número de novos visitantes podem contribuir no ato de verificar se o planejamento foi atingido na totalidade ou se é preciso fazer algum ajuste.

O monitoramento permite pôr em prática o relacionamento entre a empresa e o cliente nas mídias sociais, um dos fatores mais importantes da utilização delas.

Ainda, no monitoramento devem ocorrer as reuniões de oportunidade, nas quais juntam-se os envolvidos na gestão de um produto para ver os resultados, tomar decisões e gerar novas ideias com base na conjuntura. $\mathrm{O}$ monitoramento e análise das mídias sociais devem ser apresentados e discutidos entre todos os encarregados e interessados frequentemente, para que se decida se existem novos caminhos a serem tomados ou se é necessária alguma alteração nas estratégias de suas mídias sociais.

A aplicação do monitoramento deve ser contínua e mantida pela empresa e profissionais qualificados envolvidos todo o tempo. 


\section{MAPEAMENTO DO USO DE MÍDIAS SOCIAIS}

O universo do segmento de vestuário do Alto Vale do Itajaí é constituído por 43 empresas associadas ao Sindicato das Indústrias da Fiação, Tecelagem, Confecção e do Vestuários do Alto Vale do Itajaí, e outras 5 não associadas, mas que são consideradas expressivas na região.

Desse total de 48, a amostragem da pesquisa se ateve à participação de 26 empresas, uma vez que 2 não quiseram participar, com 3 delas não foi possível o contato e 17 não responderam até a finalização do período estipulado para respostas. $\mathrm{O}$ período para participação das empresas na pesquisa foi de 22 dias.

A pesquisa foi composta por 31 questões sobre a utilização, investimentos e situação da comunicação e das mídias sociais das empresas entrevistadas. Quanto à forma das questões, foram usadas perguntas abertas e de múltipla escolha e, quanto ao objetivo, foram empregadas perguntas de fato e de intenção.

A coleta de dados ocorreu por meio de um formulário disponibilizado pelo Google Forms. Para a participação na pesquisa, foi feito contato por telefone com os profissionais encarregados ou responsáveis pelo setor de Marketing de cada empresa. Assim que colhidos os nomes e seus endereços de e-mail, foi realizado um convite para esses profissionais participarem da pesquisa.

Percebe-se que o perfil das empresas entrevistadas é bastante diversificado: quanto aos números de empregados, o porte das empresas flutua entre 3 e 120 funcionários.

Com exceção de uma empresa com fundação em 1970, todas as entrevistadas tiveram sua criação entre 1989 e 2012, tendo praticamente a cada ano desse período uma ou mais de uma empresa sido criada. A maioria das entrevistadas estão localizadas em Rio do Sul, mas também participaram da pesquisa empresas das cidades de Lontras, Laurentino e Ituporanga.

\subsection{ANÁLISE DOS DADOS COLETADOS}

Após a coleta de dados, foi iniciada a análise como se apresenta a seguir.

No gráfico 1, é possível verificar que a maior parte das empresas entrevistadas $(38 \%)$ produz jeans e $19 \%$, jeanswear. O restante divide-se em: $8 \%$ moda, $4 \%$ moda 
íntima, $4 \%$ moda infantil e $27 \%$ comercializam outros tipos de produtos, que compõem o grupo de moda feminina, alfaiataria, fitness ou moda plus size.

\section{Gráfico 1 - Produto Comercializado}

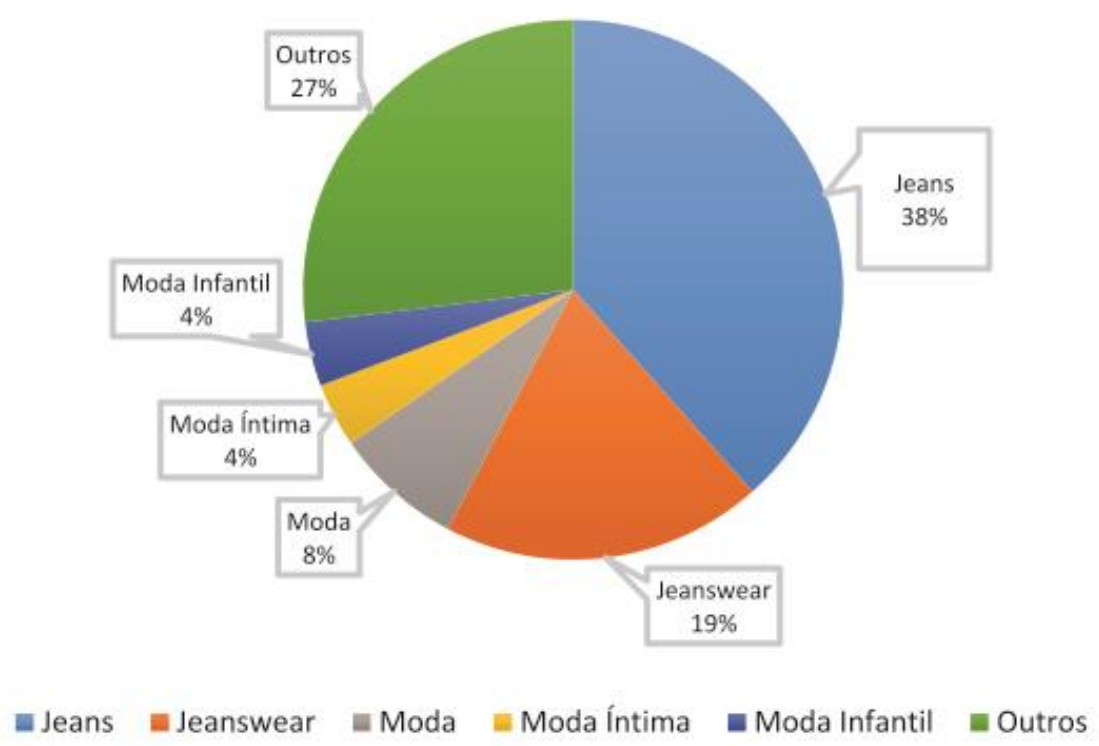

Fonte: 0 autor

Quanto à região ou estado em que as empresas atuam, percebe-se que $46 \%$ operam em alguns estados brasileiros, $23 \%$ em todo o Brasil, $12 \%$ na região Sul do Brasil e $12 \%$ apenas em Santa Catarina. Apenas $8 \%$ das empresas entrevistadas atuam somente no Alto Vale do Itajaí.

No gráfico 2, percebe-se que $62 \%$ das empresas não possuem departamentos de Marketing, Comunicação e/ou Design Gráfico, enquanto 31\% possuem departamento de Marketing, $12 \%$ de Comunicação e $8 \%$ de Design Gráfico. Quando questionadas sobre a intenção de implementar algum desses departamentos, 31\% das empresas responderam que preferem terceirizar o serviço, $23 \%$ pretendem implementar em breve, $23 \%$ futuramente, e outros $23 \%$ responderam que não pretendem implementar.

O gráfico 3 mostra que $62 \%$ das empresas entrevistadas investem em Marketing e Comunicação. Apenas $31 \%$ das empresas investem em Design Gráfico e $12 \%$ das entrevistadas responderam que não investem em nenhuma das três áreas. 
Gráfico 2 - Departamentos de Marketing, Comunicação e/ou Design Gráfico

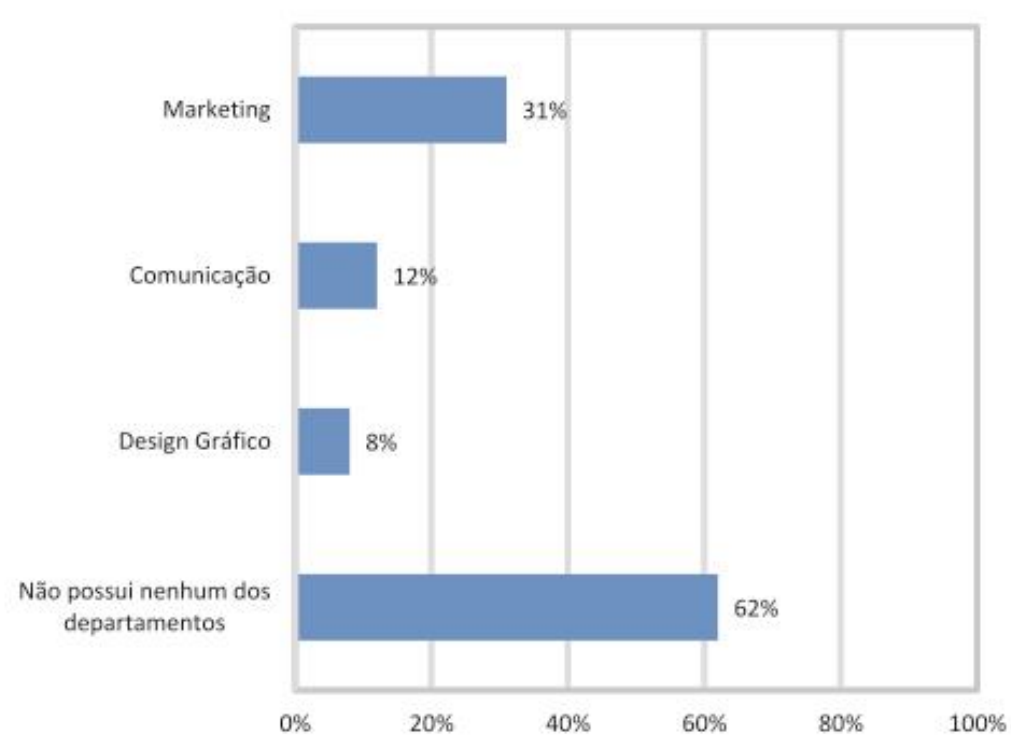

Fonte: o autor

Gráfico 3 - Investimento em Marketing, Comunicação e/ou Design Gráfico

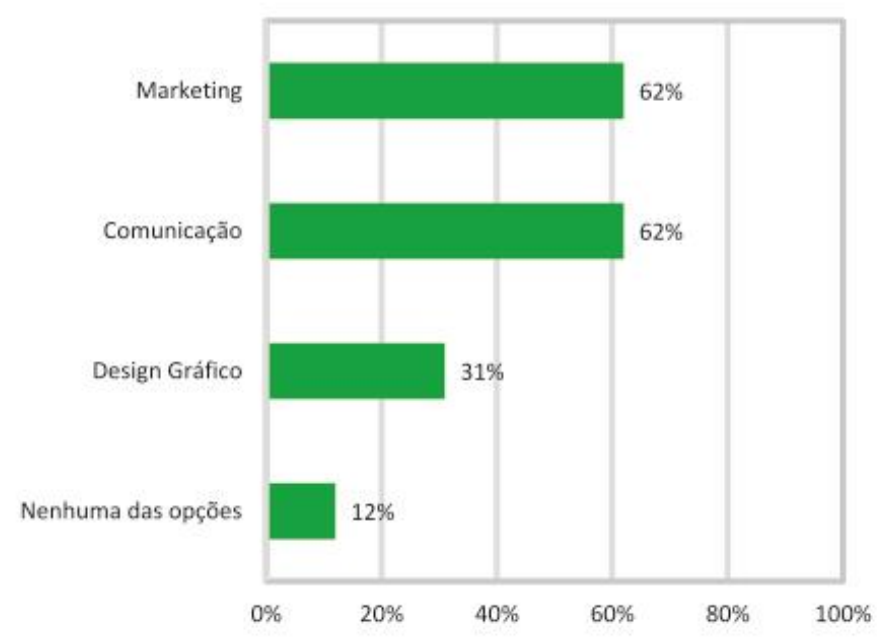

Fonte: o autor 
Quando questionadas sobre os meios de comunicação, 81\% afirmaram já ter utilizado catálogo para transmitir a sua mensagem para o público alvo; mídias sociais já foram utilizadas por $73 \%$ e outdoor, por $69 \%$.

Quando questionadas sobre quais meios as empresas utilizam frequentemente, as mídias sociais se destacam por serem utilizadas por $73 \%$ das entrevistadas, $73 \%$ utilizam catálogo e $54 \%$ anunciam em outdoor.

\section{Gráfico 4 - Ferramentas de Marketing Digital}

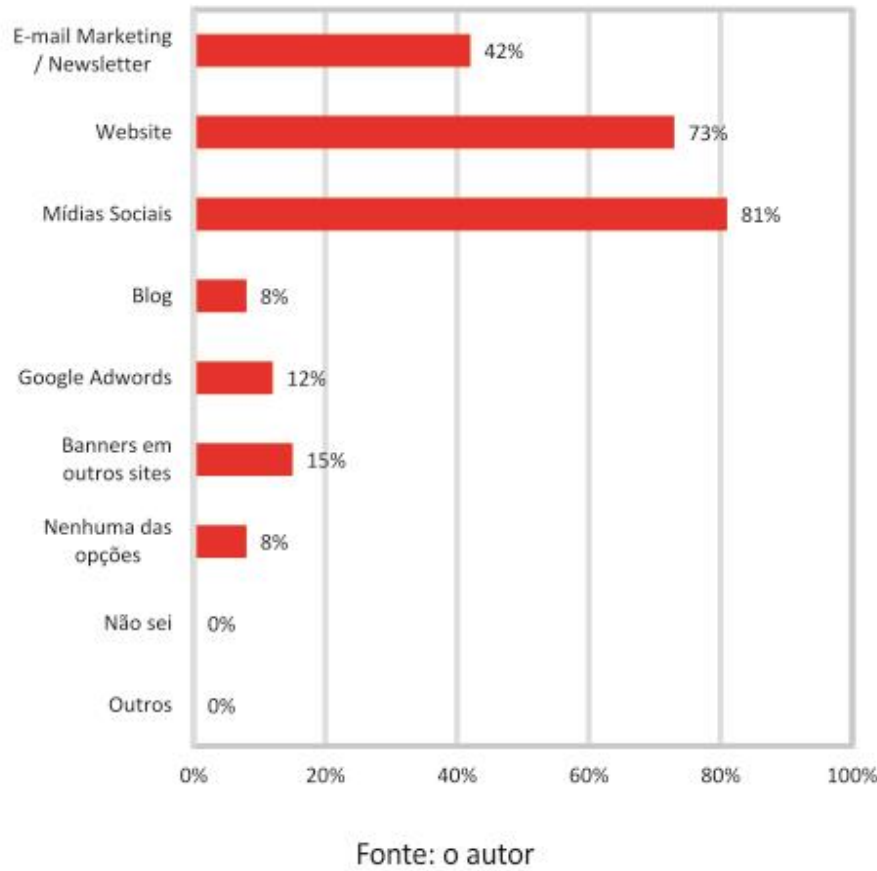

Com relação ao uso de ferramentas de marketing digital, o gráfico 4 mostra que as mídias sociais foram citadas por $81 \%$ das empresas entrevistadas, seguidas pelo website com $73 \%$ e e-mail marketing com $42 \%$.

Quando perguntadas se fazem planejamento estratégico para a comunicação, 31\% das empresas responderam que fazem semestralmente e $8 \%$ anualmente. Do total, $15 \%$ não fazem; $23 \%$ não fazem, mas pretendem fazer; e outros $23 \%$ pensam em talvez fazer no futuro. 


\section{Gráfico 5 - Planejamento Estratégico para Comunicação}

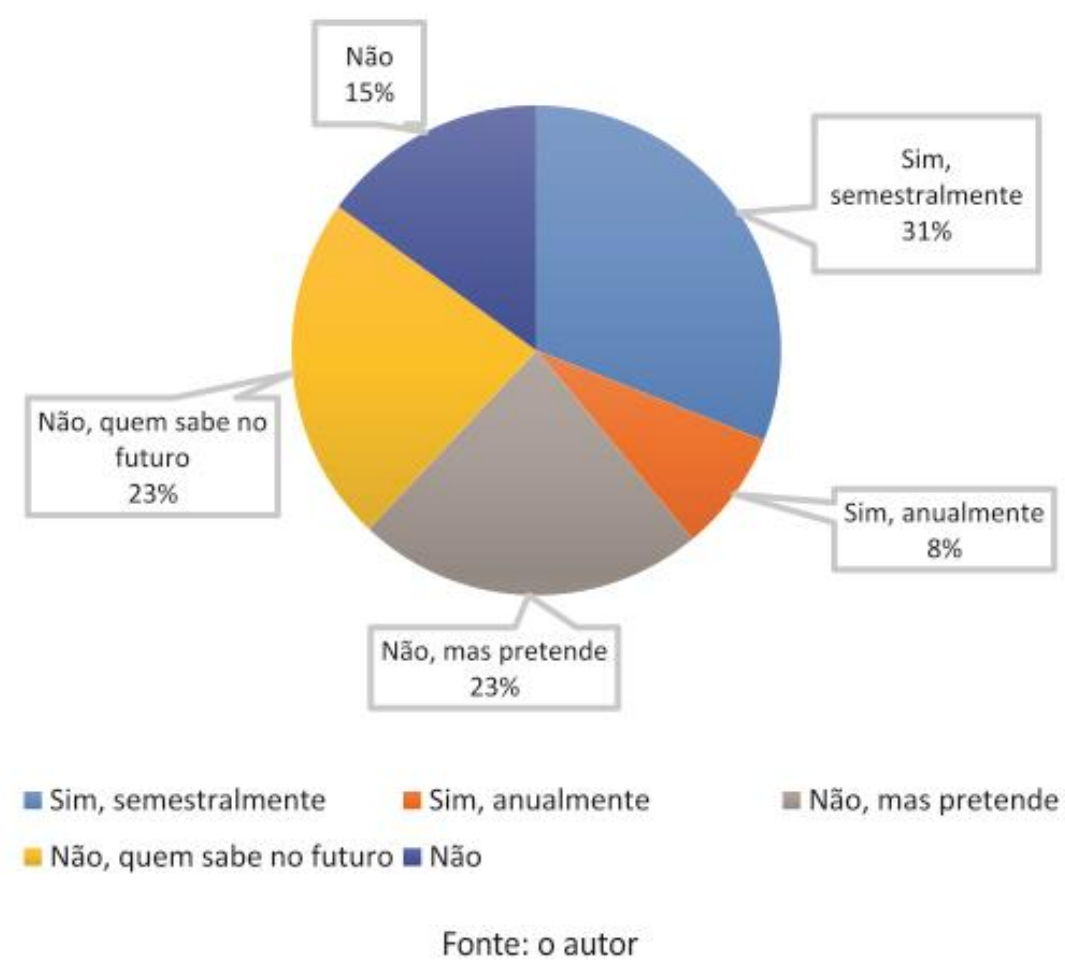

No gráfico 6, percebe-se que o Facebook abriga 88\% das empresas entrevistadas, enquanto o Instagram $35 \%$, o Twitter, $19 \%$ e o Pinterest, $8 \%$. Entretanto $12 \%$ não utilizam nenhuma mídia social e 4\% assinalaram a opção "outros", mencionando dentro da pesquisa, as mídias sociais YouTube e Vimeo. 


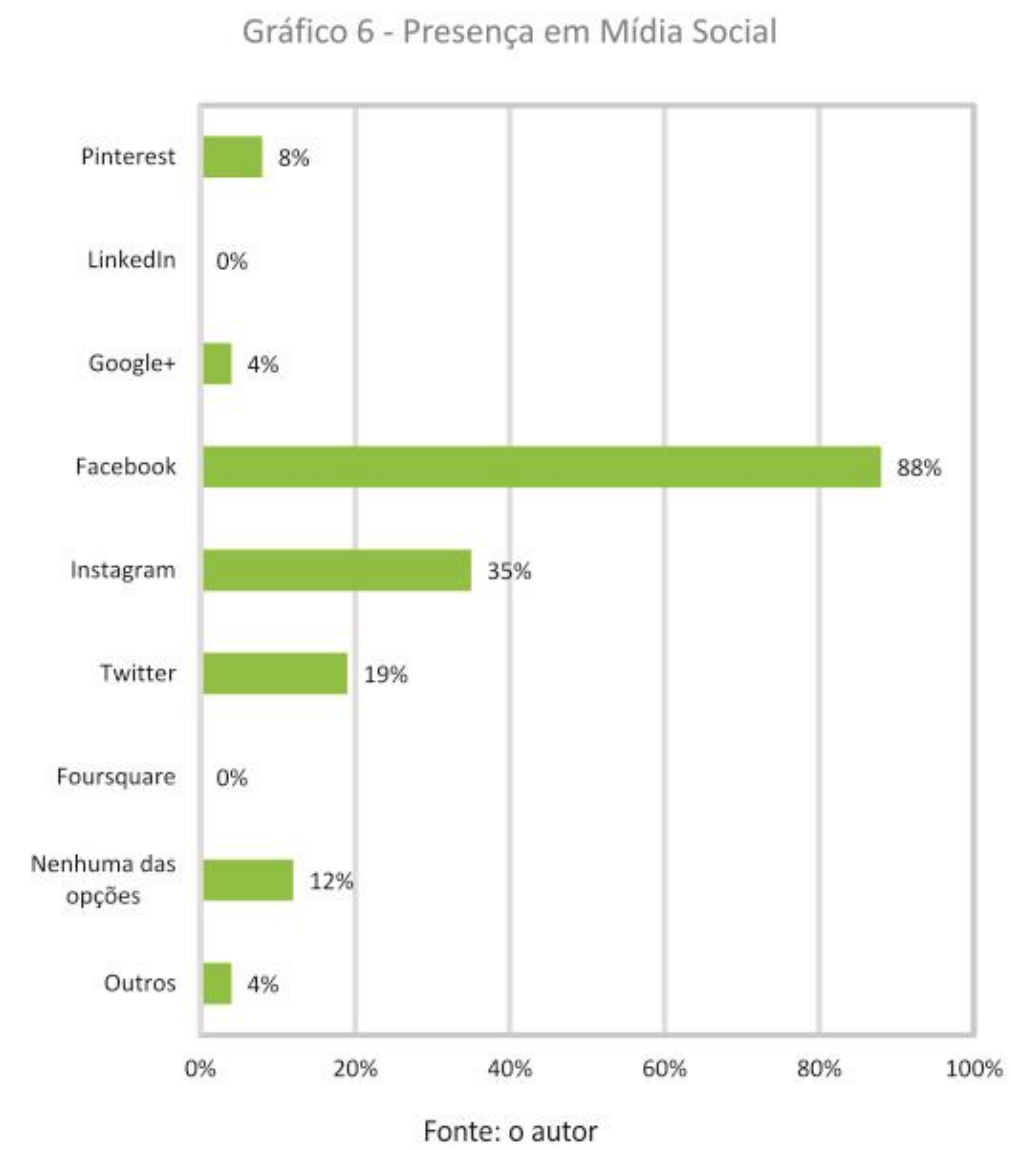

O gráfico 7 apresenta quais das mídias sociais assinaladas anteriormente as empresas utilizam com mais frequência. O Facebook segue em primeiro, sendo utilizado por $88 \%$ das empresas e o Instagram por $31 \%$; $12 \%$ não utilizam nenhuma mídia social e 4\% continuaram assinalando a opção "outros", mencionando dentro da pesquisa as mídias YouTube e Vimeo. 
Gráfico 7 - Mídia Social com Uso Frequente

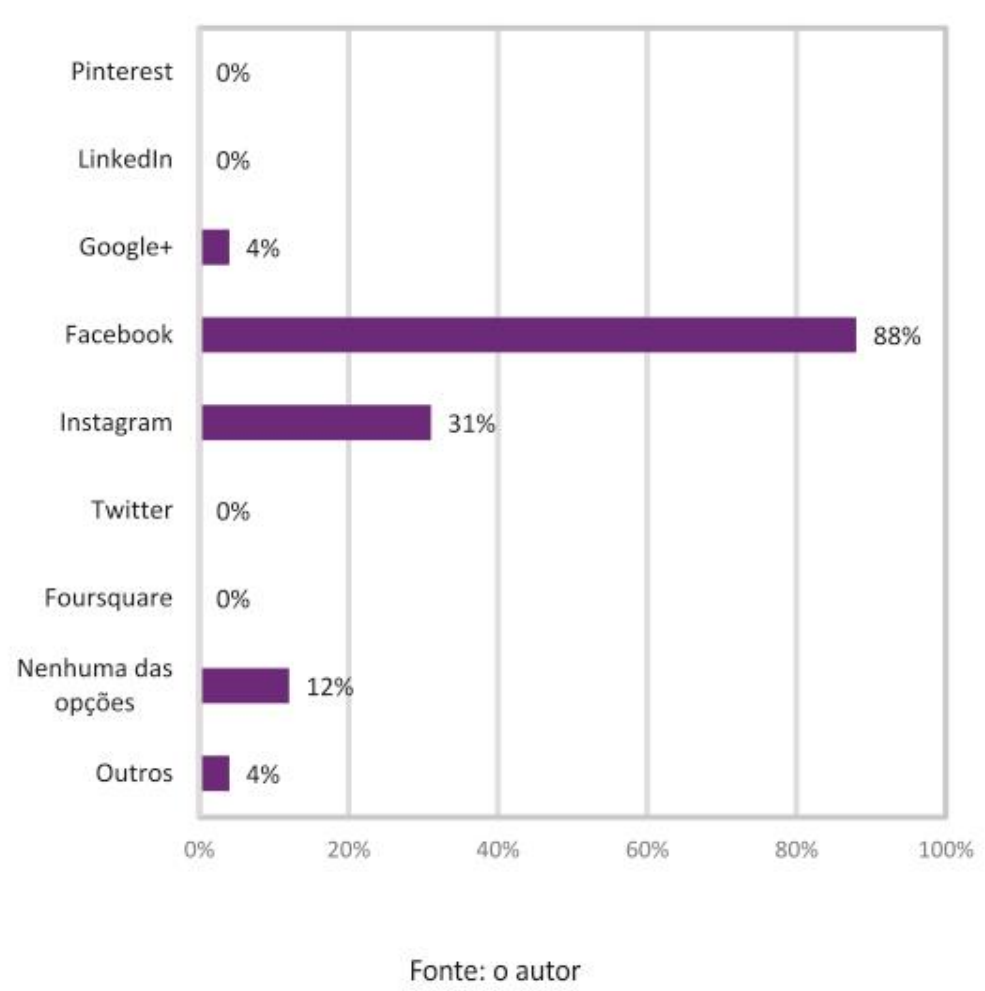

Os gráficos 8 a 13 são referentes apenas a uma parte das empresas entrevistadas as que possuem presença frequente em mídias sociais. Em todas as questões, as empresas tiveram a opção de não responder.

O gráfico 8 revela que $27 \%$ das empresas entrevistadas possuem um funcionário gerenciando suas mídias sociais. Em 19\% das empresas quem gerencia a mídia social é o próprio entrevistado que, de acordo o preenchimento no perfil da pesquisa, enquadrou-se em uma das seguintes opções de cargo: ser da administração, do setor de estilo, da área digital ou o proprietário. Das empresas, 19\% possuem um profissional terceirizado para gerenciar suas mídias sociais e $15 \%$ uma empresa terceirizada. Por fim, $8 \%$ das empresas possuem um funcionário especializado na área de Marketing, Comunicação ou Jornalismo. 
Gráfico 8 - Responsável pelas Mídias Sociais

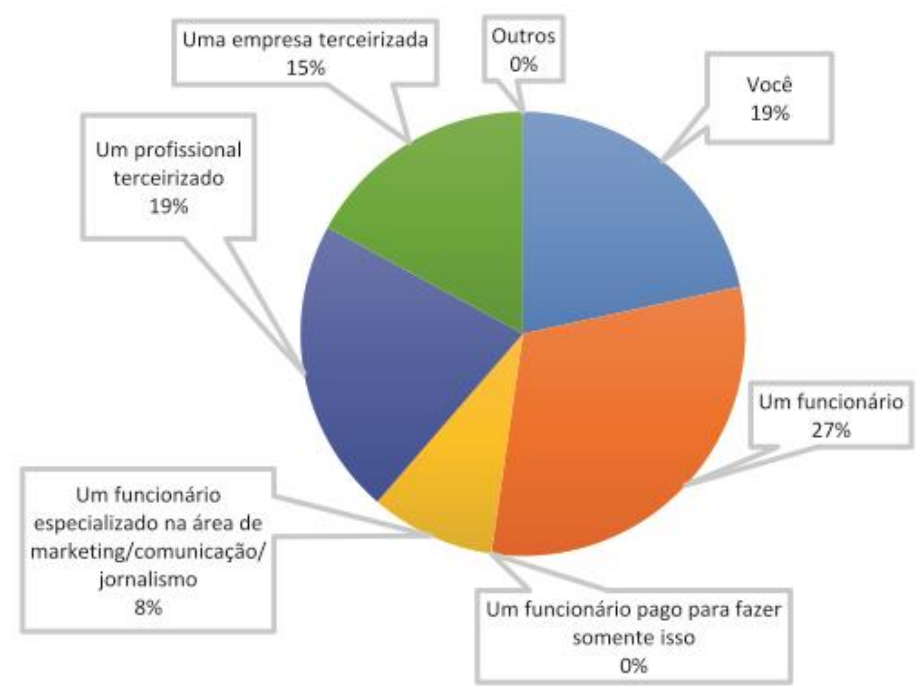

- Você (entrevistado)

- Um funcionário

= Um funcionário pago para fazer somente isso

ఐ Um funcionário especializado na área de marketing/comunicação/jornalismo

- Um profissional terceirizado

- Uma empresa terceirizada

- Outros

Fonte: 0 autor

Sobre a comunicação com o cliente por meio das mídias sociais, ou seja, o ato de interagir e responder às mensagens e comentários feitos em suas mídias sociais, o gráfico 9 mostra que a maioria das empresas, 54\%, afirmaram fazer isso quase sempre (praticamente todos os dias) e apenas $15 \%$ responderam que fazem sempre, ou seja, todos os dias ou até na mesma hora. Do total, $8 \%$ fazem mensalmente ou sem frequência definida e $8 \%$ dos entrevistados não interagem ou respondem aos seus usuários. 
Gráfico 9 - Comunicação com o Cliente pelas Mídias Sociais

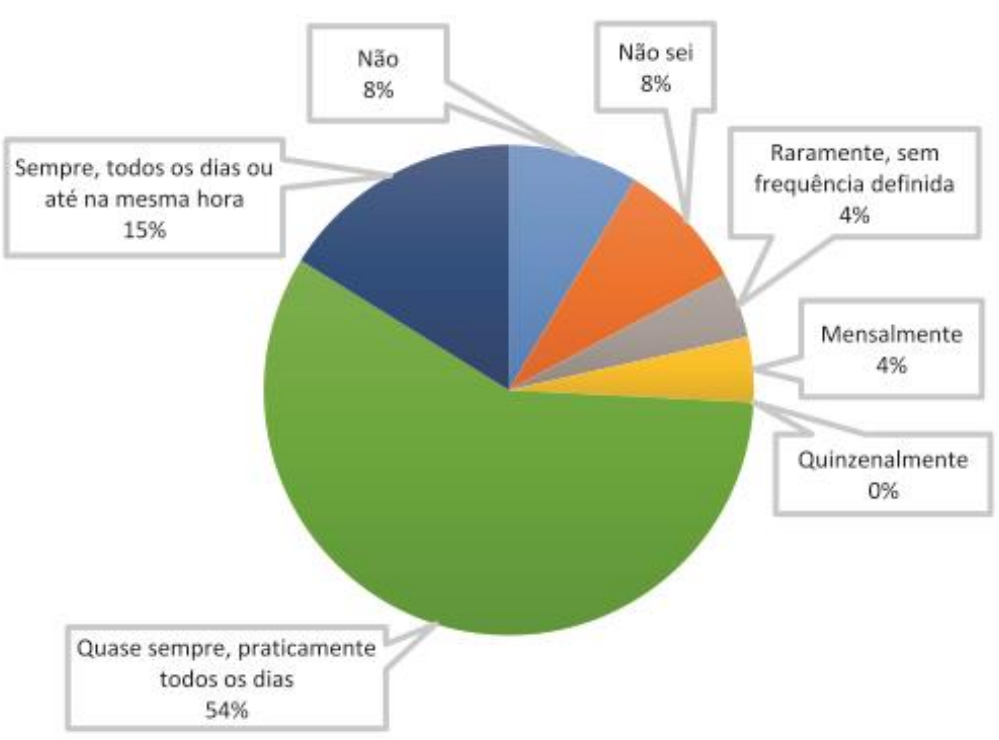

\section{- Não}

a Raramente, sem frequência definida

auinzenalmente

- Sempre, todos os dias ou até na mesma hora

Fonte: o autor

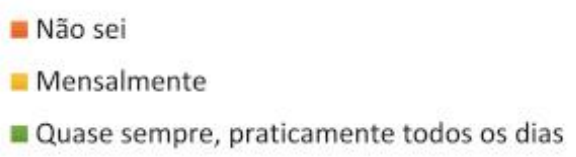

O gráfico 10 apresenta os tipos de conteúdo que são publicados pelas empresas em suas mídias sociais. A opção "Produtos e lançamentos" foi a mais selecionada, estando presente na escolha de $73 \%$ das empresas entrevistadas. "Novidades sobre a empresa" foi selecionada por 50\%, "Dicas, notícias e matérias" por 35\%, "Promoções" por $27 \%$ e "Conteúdo retirado de outras páginas e sites" por 23\%. Publicações com "Conteúdo original" foram selecionadas por 23\% e "Conteúdo lúdico (tirinhas, frases, piadas, etc.)" por $12 \%$ das empresas. 


\section{Gráfico 10 - Tipos de conteúdo que são publicados}

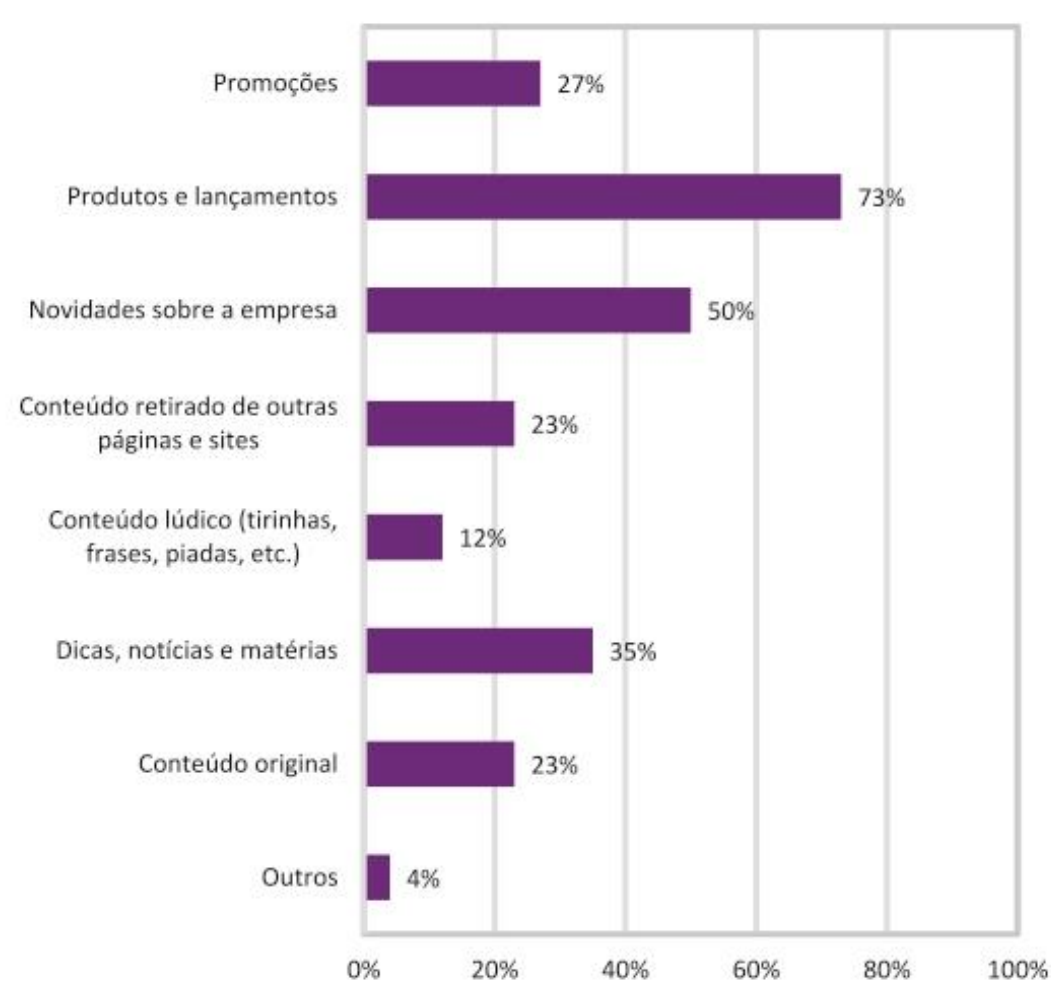

Fonte: o autor

O gráfico 11 trata do monitoramento realizado pelas empresas entrevistadas, quando questionadas sobre a frequência de análise de dados, números e métricas de suas mídias sociais: $31 \%$ responderam que não fazem, $19 \%$ que fazem há vezes, $15 \%$ quase sempre e apenas $12 \%$ realizam sempre. Enquanto isso, $8 \%$ responderam que ocorre raramente e outros $8 \%$ que não fazem, mas têm interesse; $4 \%$ não souberam responder. 
Gráfico 11 - Monitoramento das Midias Sociais.

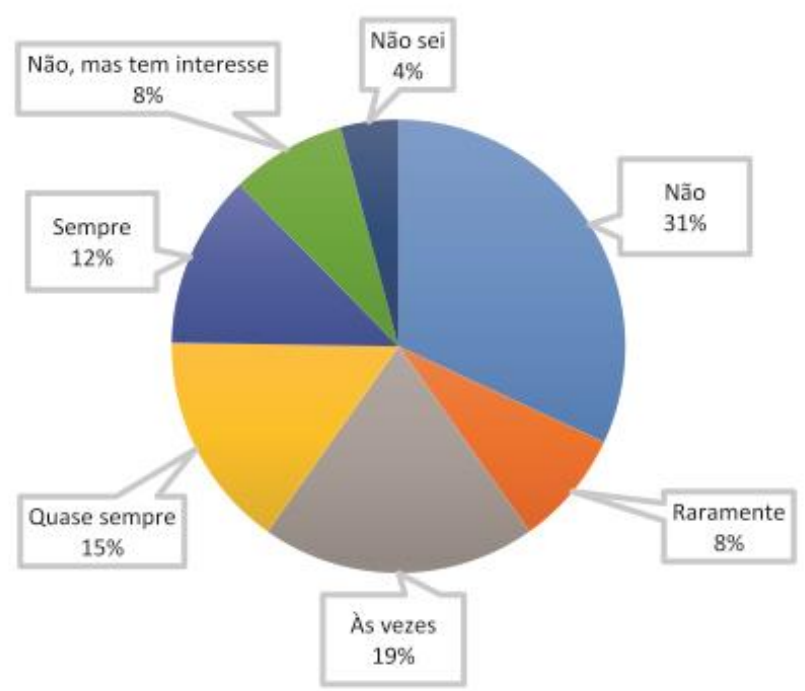

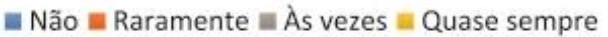

" Sempre = Não, mas tem interesse = Não sei

\section{Fonte: $\mathrm{o}$ autor}

Gráfico 12 - Planejamento Estratégico para as Mídias Sociais

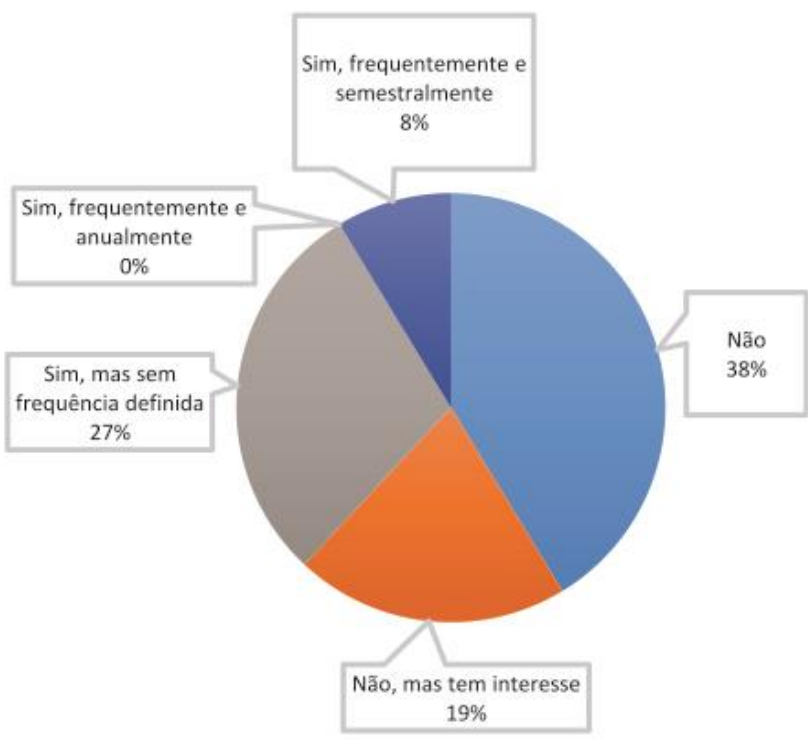

" Não

n Não, mas tem interesse

- Sim, mas sem frequência definida

= Sim, frequentemente e anualmente

a Sim, frequentemente e semestralmente

Fonte: $\mathrm{o}$ autor 
No gráfico 12 é possível verificar que 38\% das empresas não fazem planejamento estratégico para as suas mídias sociais; $19 \%$ não fazem, mas tem interesse; $27 \%$ fazem, mas sem uma frequência definida e apenas $8 \%$ fazem semestralmente.

\section{Gráfico 13 - Monitoramento das Mídias Sociais}

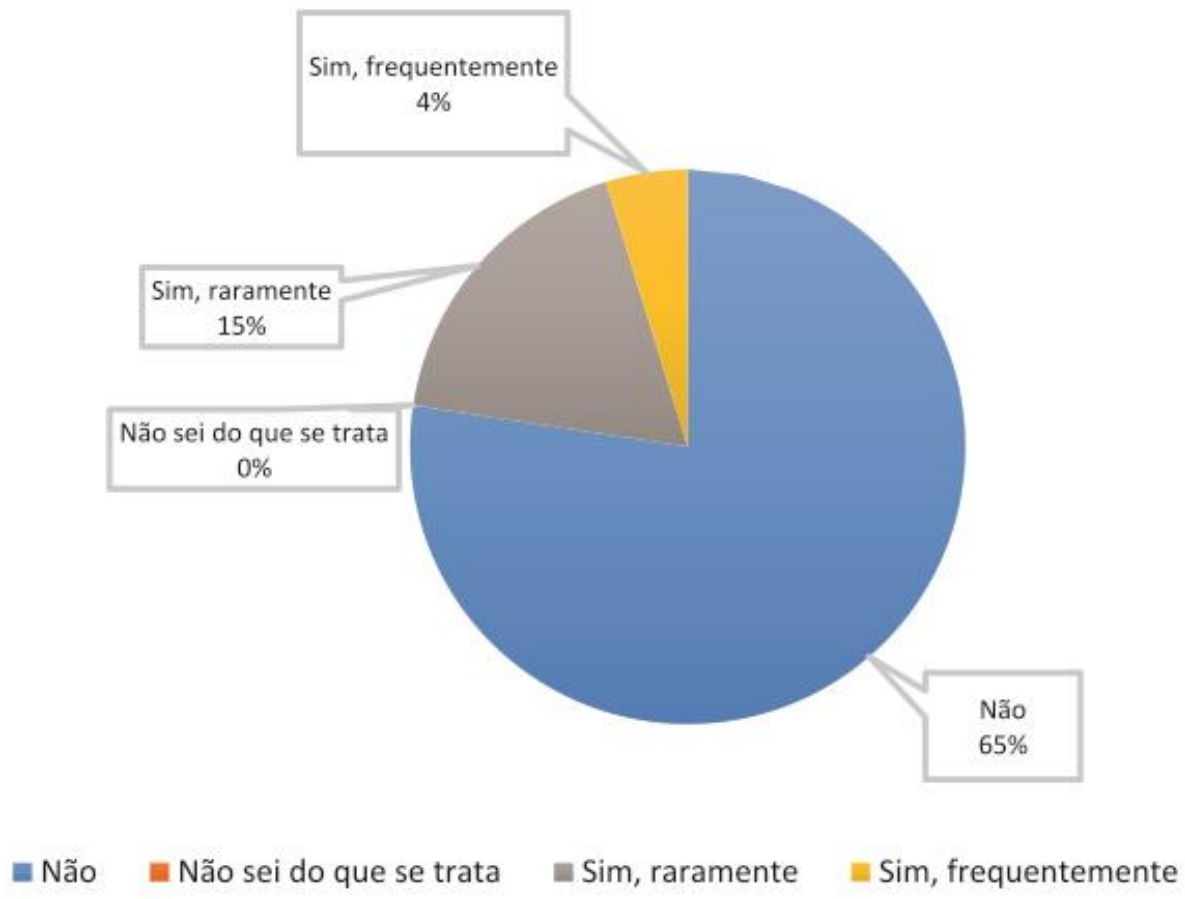

Fonte: 0 autor

E por fim, o gráfico 13 mostra que $65 \%$ das empresas não investem em anúncios pagos dentro das mídias sociais, enquanto $15 \%$ investem raramente e apenas $4 \%$ frequentemente.

\section{CONCLUSÕES}

Ao mapear o uso das mídias sociais pelo segmento de vestuário do Alto Vale do Itajaí, conclui-se que existe um campo extraordinário a ser explorado e trabalhado pela área de Marketing, Comunicação e Design Gráfico. Por meio dos dados obtidos com o questionário realizado, pode-se verificar que $62 \%$ das empresas entrevistadas não possuem departamento de Marketing, Comunicação e Design Gráfico, enquanto 31\% possuem departamento de Marketing e 12\% de Comunicação. Das empresas entrevistadas, $46 \%$ pretendem implementar, enquanto $31 \%$ preferem terceirizar este 
serviço. O investimento em Marketing acontece em 62\% das empresas; em Comunicação, 62\% e em Design Gráfico, apenas 31\%. Ou seja, pode-se destacar que existe certa conscientização por parte das empresas sobre a importância do investimento nessas áreas, e também um campo ainda a ser explorado.

Os dados também revelam que $77 \%$ das empresas utilizam as mídias sociais, tornando-se o meio mais utilizado pelas empresas entrevistadas para se comunicar com seus clientes e público-alvo. Entretanto, apenas 39\% delas fazem um planejamento estratégico para a sua comunicação, sendo ele feito semestralmente ou anualmente, enquanto $46 \%$ não fazem, mas pretendem fazer futuramente.

Os números sobre a utilização das mídias sociais deixam claro que muitas empresas já estão utilizando esse meio digital. Dentro dos dados apresentados, pode-se destacar que as mídias sociais mais utilizadas são: Facebook, Instagram, Twitter e Pinterest. Isso demonstra uma certa familiarização das empresas com o Facebook e o Instagram. Embora essas sejam as mídias sociais mais utilizadas pelos brasileiros, o Twitter, o Pinterest e até mesmo o LinkedIn (que não possui nenhuma utilização pelas empresas entrevistadas) possuem grande acesso por parte do público-alvo. O Twitter, por exemplo, tem mais usuários brasileiros que o próprio Instagram, segundo a pesquisa da agência We Are Social. Além disso, em cada um desses canais existe a possibilidade de serem trabalhadas outras formas de conteúdo, diversificando assim o material fornecido ao cliente. Porém, essas mídias sociais não são ou pouco são exploradas pelo segmento mapeado.

Outros números que demonstram que esse segmento é um ótimo campo a ser explorado são que $27 \%$ das empresas utilizam um funcionário não qualificado invés de um profissional da área para exercer o papel de gestor de suas mídias sociais e que em $19 \%$ das empresas quem gerencia é o próprio entrevistado que, de acordo o preenchimento no perfil da pesquisa, enquadrou-se em uma das seguintes opções de cargo: ser da administração, do setor de estilo, da área digital ou o proprietário. Das entrevistadas, somente $38 \%$ possuem empresa ou profissional terceirizado para gerir suas mídias sociais e $8 \%$ um funcionário especializado.

Posto isso, fica perceptível a falta de profissionalismo empregada nas mídias sociais da maioria das empresas entrevistadas. Esse é um fator que pode influenciar - e muito - no trabalho executado nas mídias sociais e no seu resultado, tendo em vista que 
o encarregado ou a equipe envolvida na gestão de qualquer mídia social deve ter conhecimento em Comunicação, Marketing, Design e/ou Publicidade; caso contrário, é provável que existam falhas ou futuro insucesso na utilização desses canais.

Além desses dados, e a respeito da utilização das mídias sociais, alguns pontos devem ser destacados.

Um ponto positivo das empresas entrevistadas é que $69 \%$ delas interagem praticamente todos os dias e ou até na mesma hora com o seu público. Afinal, as mídias sociais são canais de comunicação e o principal motivo para estar nelas é justamente a relação que se pode construir com o próprio público-alvo e clientes. Se não for para interagir e se comunicar com os clientes todo o tempo, não adianta estar presente nas mídias sociais.

Sobre qual tipo de conteúdo publicado em suas mídias sociais, a maioria das empresas respondeu "Produtos e lançamentos" (73\%) e "novidades sobre a empresa" (50\%). As mídias sociais são ótimos canais para esse tipo de publicação, mas muitas empresas se esquecem de que o público busca conteúdo original e relevante, criado e pensado especialmente para ele. A opção “dicas, notícias e matérias" é utilizada por $35 \%$ das empresas e apenas $23 \%$ delas trabalham com "conteúdo original" em suas mídias sociais.

Outro ponto importante a ser considerado a respeito da monitoração/análise de dados é que apenas $27 \%$ das empresas o fazem quase sempre ou sempre, enquanto $43 \%$ não fazem ou não souberam responder se fazem. Ou seja, é provável que a maioria das empresas entrevistadas não sabem ondem estão acertando ou errando nas mídias sociais.

E por fim, destaca-se que $38 \%$ das empresas não fazem planejamento estratégico para as mídias sociais, deixando-as, assim, à mercê da imprevisibilidade. Em contrapartida, $19 \%$ não fazem, mas têm interesse.

Embora já exista um entendimento sobre a importância do uso das mídias sociais, as empresas estão utilizando-as de maneira não planejada, afinal, é pequeno o grupo que realiza planejamento estratégico e monitoramento nesses canais. Assim, existe pouca exploração do potencial dessas ferramentas, sendo visível a falta de profissionalismo na área. 
No entanto, compreende-se a existência de um campo fantástico a ser explorado por profissionais da área, com a possibilidade da criação e definição de estratégias de comunicação e marketing e, junto a elas, a realização da gestão de design.

\section{Artigo recebido em Outubro de 2015. Aprovado em Dezembro de 2015 DOI:http://dx.doi.org/105965/1982615x08012015058}

\section{REFERÊNCIAS}

FRANÇA, F. A. Diversificação industrial como fator de dinâmicas territoriais: a experiência de Rio do Sul (SC). 2014. Monografia (Graduação em Ciências Econômicas) - Departamento de Economia e Relações Internacionais, Universidade Federal de Santa Catarina, Florianópolis.

GUNELIUS, S. Marketing nas mídias sociais em 30 minutos: manual prático para divulgar seus negócios pela internet de modo rápido e gratuito. São Paulo: Cultrix, 2012.

PALERMO, F. 5 passos para criar estratégia digital: como usar a internet para gerar resultado. Talk2. Disponível em http://materiais.talk2.com.br/estrategias_digitais. Acesso em 22/02/2015

TELLES, A. A revolução das mídias sociais: cases, conceitos, dicas e ferramentas. São Paulo: M. Books do Brasil, 2011.

TORRES, C. A bíblia do marketing digital: tudo o que você queria saber sobre marketing e publicidade na internet e não tinha a quem perguntar. São Paulo: Novatec, 2009.

WE ARE SOCIAL SINGAPORE. Digital, social \& mobile in 2015: we are social's compendium of global digital statistics. Disponível em http://pt.slideshare.net/wearesocialsg/digital-social-mobile-in-2015. Acesso em 26/02/2015 